\title{
Vegetative Propagation Techniques of Oxytenanthera Abyssinica in Benshangul Gumuz Region, Western Ethiopia
}

\author{
${ }^{1}$ Melkamu Abere ${ }^{*}{ }^{2}$ Dereje Gasheye, ${ }^{3}$ Belayneh Azene, ${ }^{4}$ Yigardu Mulatu \\ ${ }^{1,2,3}$ Bahirdar Environment and Forest Research Center, P.O.Box 2128, Bahirdar, Ethiopia \\ ${ }^{4}$ Ethiopian Environment and Forest Research Institute, P.O.Box 2453, Addis Ababa, Ethiopia
}

\begin{abstract}
Bamboo is a fast-growing woody perennial and grass species that has a unique feature and quality. It has a high potential for socio-economic development and for environmental improvement. The present study was conducted in Benshangul Gumuz Regional state of Western Ethiopia, a highly bamboo dominated area. This study aims to identify the best vegetative propagation technique for Oxytenanthera abyssinica species. The propagation materials tested were off-set, rhizome without nodes, rhizome with two nodes and whole Culm. The survival rate, the number of newly sprouted shoots; their length and the root collar increment data were collected. There was a significant difference in the number of newly emerged shoots among the propagation methods applied. Higher numbers of sprouted shoots and survival rates were recorded in the treatments including off-sets and rhizomes with two nodes than the remaining treatments of rhizomes without nodes and whole Culm. Moreover, there was a significant difference of shoot length among the different propaguoles, while on the other hand; there was no significant difference in root collar diameter among the treatments. The findings suggest that two-node rhizome propagation technique is more appropriate for large and small-scale plantations of Oxytenanthera abyssinica.
\end{abstract}

Keywords: Bamboo, Culm, Off-set, Rhizome and Shoot .

\section{Introduction}

Bamboo is a fast-growing woody perennial belonging to the family of grasses, Gramineae (Poaceae), with unique features (Bareja, 2010). It is evergreen plant that produces primary shoots without later secondary growth. Each shoot has a distal aerial part,aproximal ground level part, a subterranean part called culm, culm neck and rhizome respectively. Culms consist of nodes and internodes with meristematic (Kleinhennz and Midmore, 2005).Bamboo is also a versatile renewable resource with a high potential for socio-economic development and environmental improvement (Rao et al.,1996;Kassahun, 2000).

Ethiopia has two indigenous bamboo species: the African Alpine Bamboo (Yushane alpine K. Shumann Lin; synonym: Arundinaria alpine K. Schumann) and the monotypic genus Oxytenanthera abyssinica (A. Richard) Munro. These species are also found in some other African countries, but nowhere else outside the African continent. Ethiopia contributes the largest coverage of bamboos in Africa, giving out more than 1 million hectares. This constitutes about $67 \%$ of the total area of bamboo on the continent (Kassahun, 2000; Yeshambel,et al.,2011;Abiy, 2013).

Bamboo has diverse socio-economical (goods), environmental and ecological importance (services) at local, regional, national and global levels (Yohanneset al., 2018). In Ethiopia, bamboo has significant role in providing employment and economic growth opportunities for rural and urban communities (Mulugeta, 2013). It also contributes more in generating income since it can be processes in to products for domestic use and export market (Regassa, et al., 2016).

Flowering of Oxytenanthera abyssinica seems to be more frequent and it flowers every 30-35 years. Currently, mass flowering there by mass death has reached over $85 \%$ of the estimated total 400,000 ha bamboo region, which might havoc the whole ecosystem and lives dependent on bamboos (Demissew et al., 2011). Due to rapid increment of the country population growth the bamboo resource become declined at an 
alarming rate that demanding the resource by the local people directly and indirectly like for food, house construction and shifting the bamboo land for agricultural crops.

Concerning the above problems, the Ethiopian government has established a new Environment and Forest commission, designing afforestation and reforestation program in order to increase the forest coverage of the country. The government promotes bamboo planting of in regions of the country where steeper and higher uplands are found (Yared et al., 2017).

Bamboo naturally can be propagated either by sexual (reproductive) or asexual (vegetative) methods. Artificial propagation by vegetative methods includes planting of offsets, Culm cuttings, layering, and grafting of rhizome (Kssahunet al., 2002). Sexual propagation is accomplished through seeds (Demelash et al., 2012). However, this is not a usual propagation method in Ethiopia due to the irregularity and rarity of the flowering of common bamboo species. Currently, since planting bamboo on a larger scale has increased in Ethiopia, cost-effective and efficient propagation techniques are required. Though, the viability of seeds of Oxytenanthera abyssinica is relatively longer (three years), ) and has a higher germination rate, seeds are not always available regularly (LUSO Consult, 1997; Azene Bekele, 2007; Demelash et al., 2012).Besides, culms produced from seed need a longer period (seven years) to reach harvestable size. Under these circumstances, other effective propagation techniques must be chosen. Clonal /vegetative propagation is cost-effective and desirable for large-scale applications (Reddy, 2006). Moreover, different parts of bamboo plants are used as propagation material, offsets, Culm cuttings, layering, and grafting of rhizome (Dereso, 2019).

A clump-based vegetative propagation technique is a time-tested and widely practiced method in Asia (Banik, 1995). A segment is severed or separated from the parent rhizome and treated to develop into an independent source of planting material. The detached part of the rhizome carries all the elements needed for the growth of a new plant. It may be separated from other parts of the plant such as rhizome, offsets, roots and Culm. Common to all methods of rhizome-based propagation is the cutting away of a part of the rhizome from a healthy and mature clump.

Nevertheless, studies on vegetative propagation of Oxytenanthera abyssinica species in Ethiopia are limited. Therefore, this study aims to establish a protocol for an effective propagation method of this bamboo at normal nursery conditions.

\section{Material and methods}

\section{Study area description}

This study was conducted in the western part of Ethiopia, Assosa as indicated. Assosa is located $12^{\circ} 58^{\prime} \mathrm{N}$ $36^{\circ} 12^{\prime} \mathrm{E}$ with an altitudinal range of 600-1200 masl; annual rainfall ranges from 800 to $1390 \mathrm{~mm}$ with a mean annual rainfall of $965 \mathrm{~mm}$, and its average monthly minimum and maximum temperature is 19.6 and $35.5^{\circ} \mathrm{C}$, respectively. The planting site was a well-drained soil on a gently sloping land. The availability of water sources was also taken into consideration, so that water supply was possible during the dry spells, up to six months of the experimental period. 


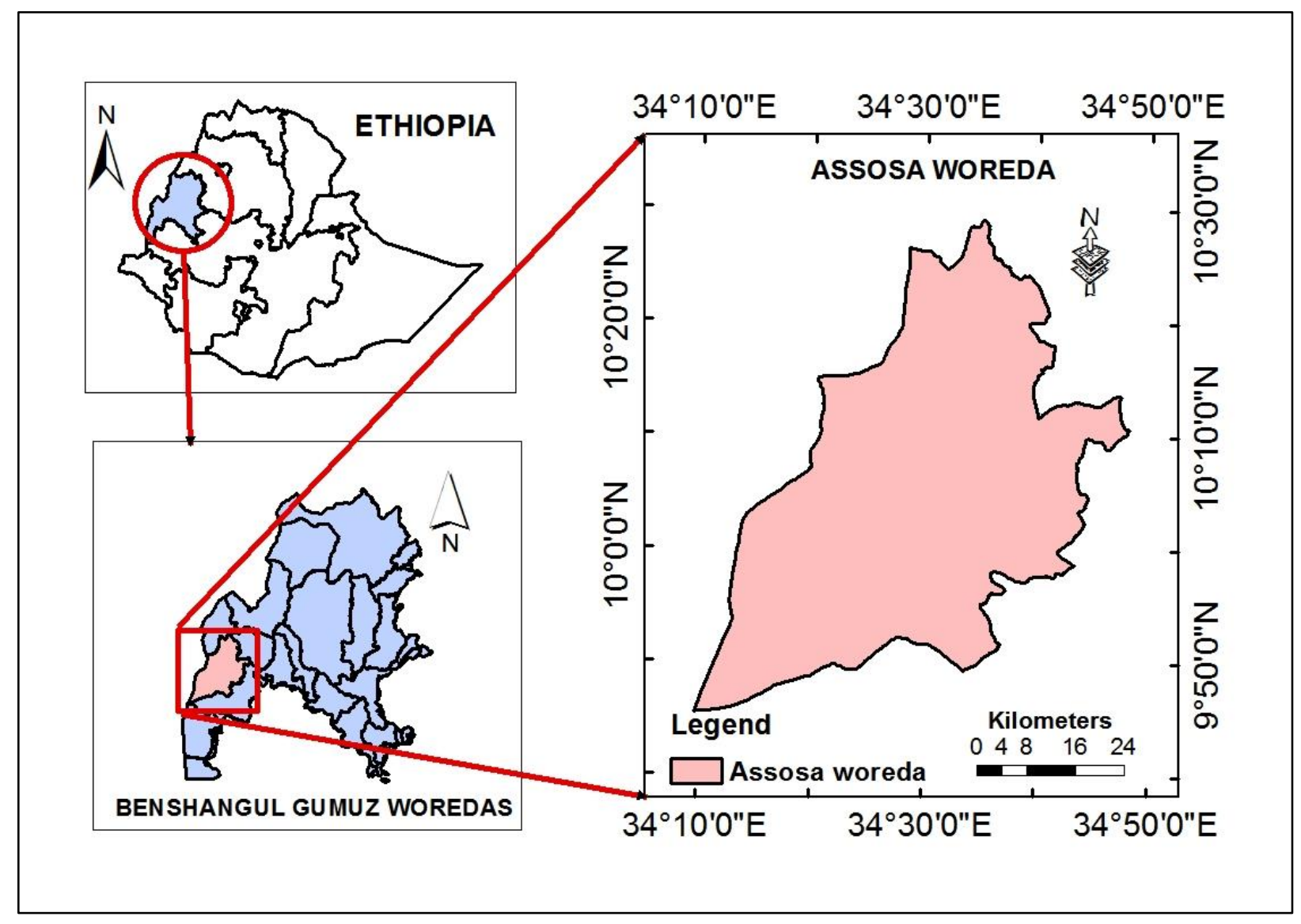

Figure 1: Area of study 


\section{Treatments and Experimental design}

For this experiment, propagation manuals of tropical bamboos by Banik (1995); Ronald (2005) were followed. As propaguoles off-set, rhizome without nodes, rhizome with two nodes and whole Culm were used. Planting materials were collected from a bamboo forest nearby Assosa town. The treatments were laid in randomized complete block design with three replications and nine planting material planted for each plot and the spacing between plants was $4 \mathrm{~m}$.

The trial was established on August $1^{\text {st }}$ 2014, when the soil was sufficiently wet, following the start of the main rainy season. Additional water was Supplying when the rain was absent more than a day from December to May. A layer of grass mulch was applied within each planting material in order to retain moisture, reduce evaporation and protect them from direct sunlight. Weeding and hoeing were done twice in each rainy season (June to October). The experiment was conducted from 2014 to 2016. The number of new shoots emerged, shoot length, root collar diameter and survival rate were recorded every six months (totally three times). Normality and homogeneity of variances were checked before the actual analysis. Data analysis was made using SPSS 20. One-way ANOVA was conducted and the Least Significance Difference (LSD) test was used.

\section{Results and Discussions}

\section{Effect of different propaguoles and time on the vegetative propagation of Oxytenanthera abyssinica Shoot Sprouts}

The average numbers of sprouted shoots of the treatments are presented in table (1). The results showed that the number of new shoots produced was significantly different among propagation methods $(P=0.02)$. The mean number of new shoots was higher in offsets and rhizomes with two nodes $(14 \pm 3.28$ and $11 \pm 1.49$, respectively) than rhizomes without nodes and whole Culm $(6.44 \pm 1.35$ and $4.11 \pm 2.25$, respectively) (Table 1). Time trends indicated that there was a statistically significant difference in the mean number of newly sprouted shoots as time progressed $(P=0.032)$ (Annex). In all propaguoles, new shoots emerged within six months after establishment of the experiment. Kassahun, (2000) stated that new bamboo shoots are produced after three years of establishment by seed. During our data collection time, more new sprouted shoots were emerged in the rainy season (Figure 2), whereas water fluctuation and termites was a strained for emerged sprouted shoots. Similar studies, (Batabyal and Tah, 2013; Yared et al.,2017) reported that the sprouting rate of shoots after planting varied with different propaguoles depicting a high number of high land bamboo shoots during the wet season. According to Yigardu and Masresha (2014) new shoots of high land bamboo were challenged by strong winds, season and water fluctuation.

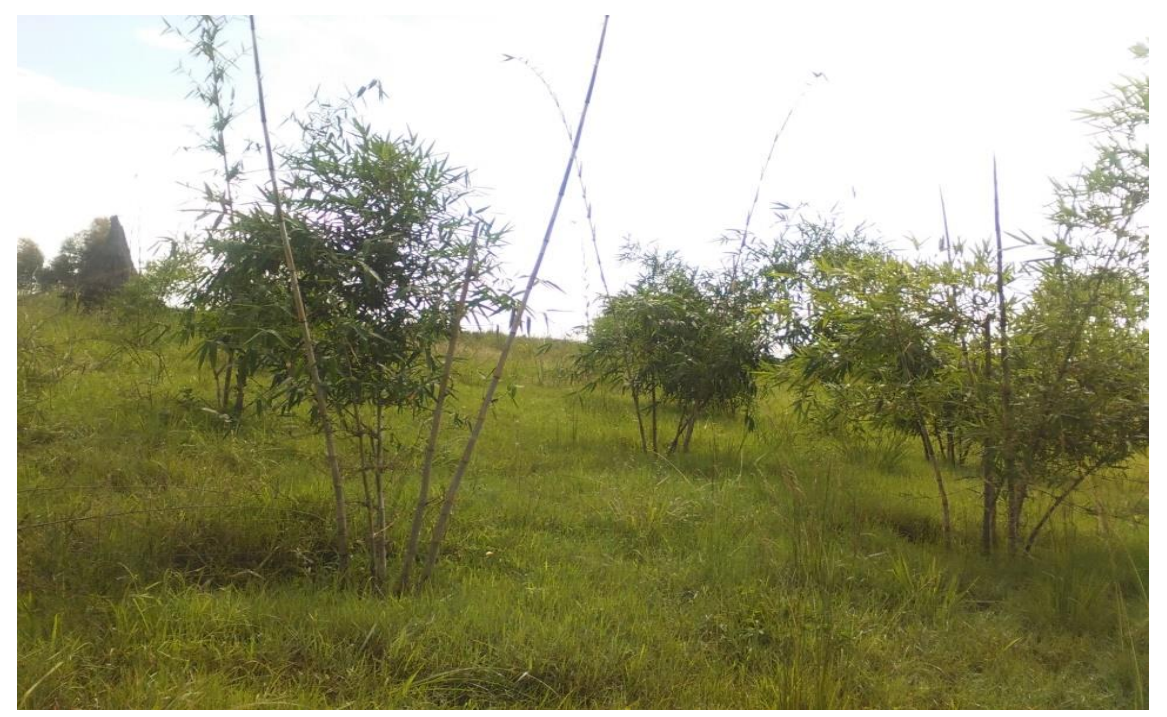

Figure 2: Sprouted shoots of Oxytenanthera abyssinica at summer season

\section{Survival rate}

The mean survival rates in different propagation techniques of Oxytenanthera abyssinica were significantly different $(P=0.00)$. Relatively higher, mean survival rates were recorded in offset and rhizome with twonode $(60.44 \pm 2.93$ and 59.32 \pm 3.25) than rhizome without nodes and whole culm $(17.42 \pm 1.64$ and 
$22.2 \pm 7.99)$ propagation techniques as indicated in table (1). The result indicated that the mean survival rate of offset had lesser differences with rhizome with two-node propagation techniques. However, Offset propagation techniques had a great difference with rhizome without node and whole Culm propagation techniques of Oxytenanthera abyssinica. The survival rate of different propagation techniques of Oxytenanthera abyssinica along consecutive ages did not significantly different $(P=0.967)$ (Annex). However, there are fewer variations of survival rates of different propagation techniques along growing ages as indicated in figure (3b). The time trend indicated that the mean survival rate of the whole Culm propagation technique was higher in the first six months but it was becoming to decrease when the growing ages increase as indicated in figure (3b). This propagation system might be indicated a false survival rate without developing roots to uptake the nutrient and water because after planting it emerged new leaf and then most of the shoot emerged plants were dried.

\section{Root collar diameter}

The average root collar diameter of different propagation techniques as described in the table below. There was no significant difference in the mean diameter increment between propagation techniques as indicated in table (1). Even though there is no statistically significant difference was observed under mean diameter increment, the higher shoot diameter increment was recorded in offset and rhizome without nodes $(15.05 \pm 3.90$ and $13.53 \pm 3.57)$ than rhizome with two nodes and whole Culm $(12.54 \pm 3.06$ and 5.47 \pm 3.44$)$ propagation techniques. As the result showed that a whole Culm propagation technique had the lowest shoot root collar diameter increments, this might be due to a lack of food storage rhizome part. The remaining three propagation techniques (off-set, rhizome without node and rhizome with two nodes) have attached with rhizome, which is helping to emerge thick shoots. A similar study in the highland bamboo (Yigardu and Masresha, 2014; Yaredet al., 2017), reported that the lowest diameter increment was recorded at whole Culm propagation techniques. There was a highly significant difference in the mean root collar diameter between all propagation techniques through time trends $(P=0.00)$ (Annex). Sprouted shoots of root collar diameter of all propagation techniques were become increased along with time trends or ages as shown in figure $(3 \mathrm{c})$.

\section{Length of sprouted shoots}

There was a significant difference in the mean height growth of sprouted shoots between propagation techniques $(P=0.03)$ as indicated in table (1).The highest average height growth of sprouted shoots was recorded in offset propagation techniques $(193 \pm 41.32)$ which compared with rhizome without node, rhizome with two nodes and whole Culm propagation techniques $(156.65 \pm 40.32 ; 163.80 \pm 29.86$ and $50.91 \pm 25.03)$ as indicated in table (1). Relatively in whole Culm propagation techniques, least sprouted shoot height increments were recorded. There was a highly significant difference in the mean height growth of sprouted shoot between all propagation techniques through time trends $(P=0.00)$ (Annex). The time trend indicated that the height means sprouted shoot of propagation techniques became increase and the highest mean shoot growth recorded at the end of the data collection period. Whereas the least mean shoot height growth was recorded at the initial period as indicated in figure (3).

Table 1:- Effect of different propaguoles on the vegetative propagation of Oxytenanthera abyssinica.

\begin{tabular}{|c|c|c|c|c|c|}
\hline \multirow{2}{*}{ Treatment } & Off-set & $\begin{array}{l}\text { Rhizome } \\
\text { without node }\end{array}$ & $\begin{array}{l}\text { Rhizome with } \\
\text { two nodes }\end{array}$ & Whole Culm & \multirow{2}{*}{$P$-value } \\
\hline & Mean \pm Std.SE & Mean \pm Std.SE & Mean \pm Std.SE & $\begin{array}{ll}\text { Mean } & \pm \\
\text { Std.SE } & \end{array}$ & \\
\hline $\begin{array}{l}\text { Number of new } \\
\text { shoots }\end{array}$ & $14 \pm 3.28$ & $6.44 \pm 1.35$ & $11 \pm 1.49$ & $4.11 \pm 2.25$ & 0.02 \\
\hline Survival rate $(\%)$ & $60.44 \pm 2.93$ & $17.42 \pm 1.64$ & $59.32 \pm 3.25$ & $22.20 \pm 7.99$ & 0.00 \\
\hline $\begin{array}{l}\text { Root collar } \\
\text { diameter }(\mathrm{mm})\end{array}$ & $15.05 \pm 3.9$ & $13.53 \pm 3.57$ & $12.54 \pm 3.06$ & $5.47 \pm 3.44$ & 0.24 \\
\hline Shoot length $(\mathrm{cm})$ & $193.7 \pm 41.32$ & $156.65 \pm 40.32$ & $163.80 \pm 29.86$ & $50.91 \pm 25.03$ & 0.03 \\
\hline
\end{tabular}




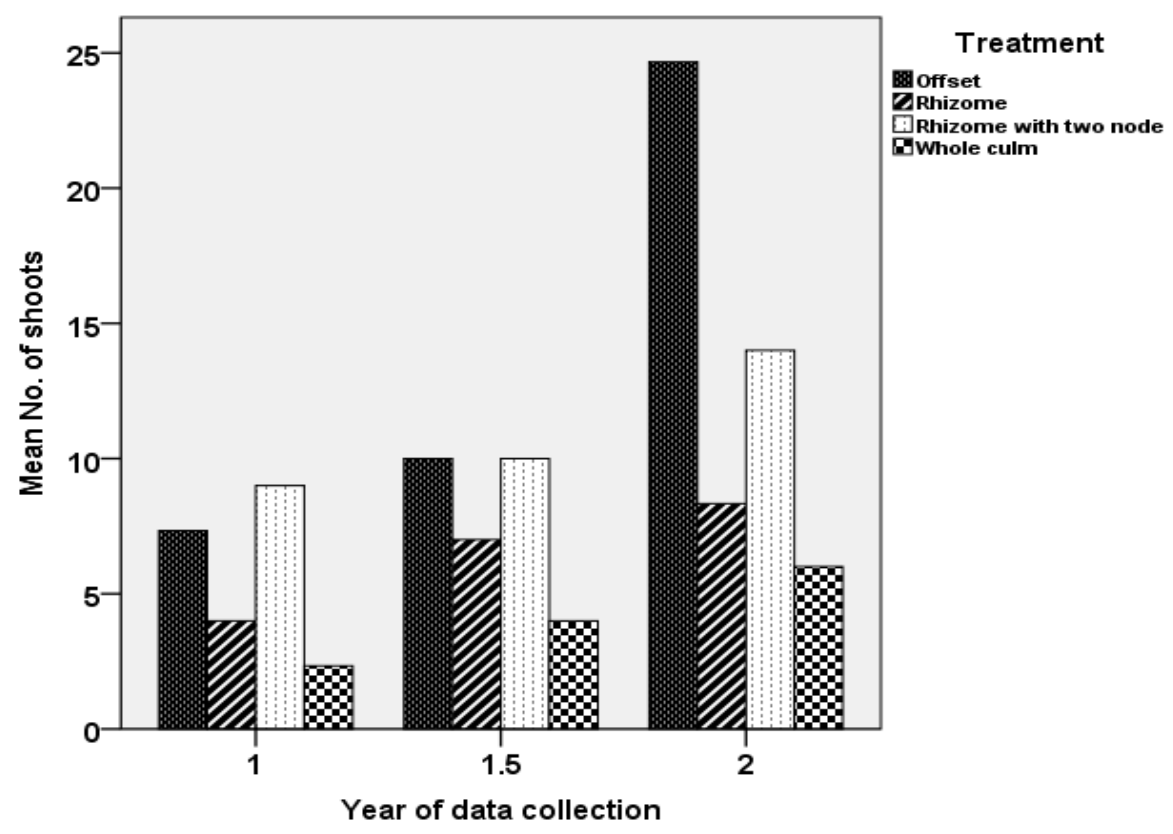

Figure a

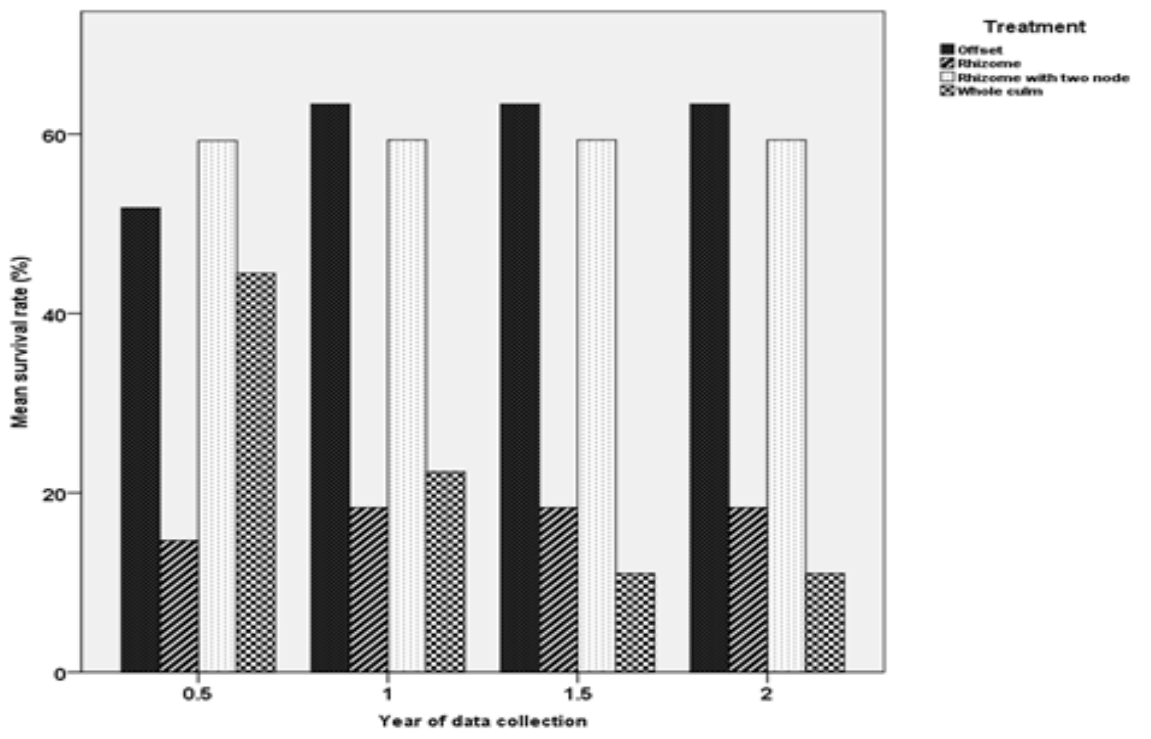

Figure b 

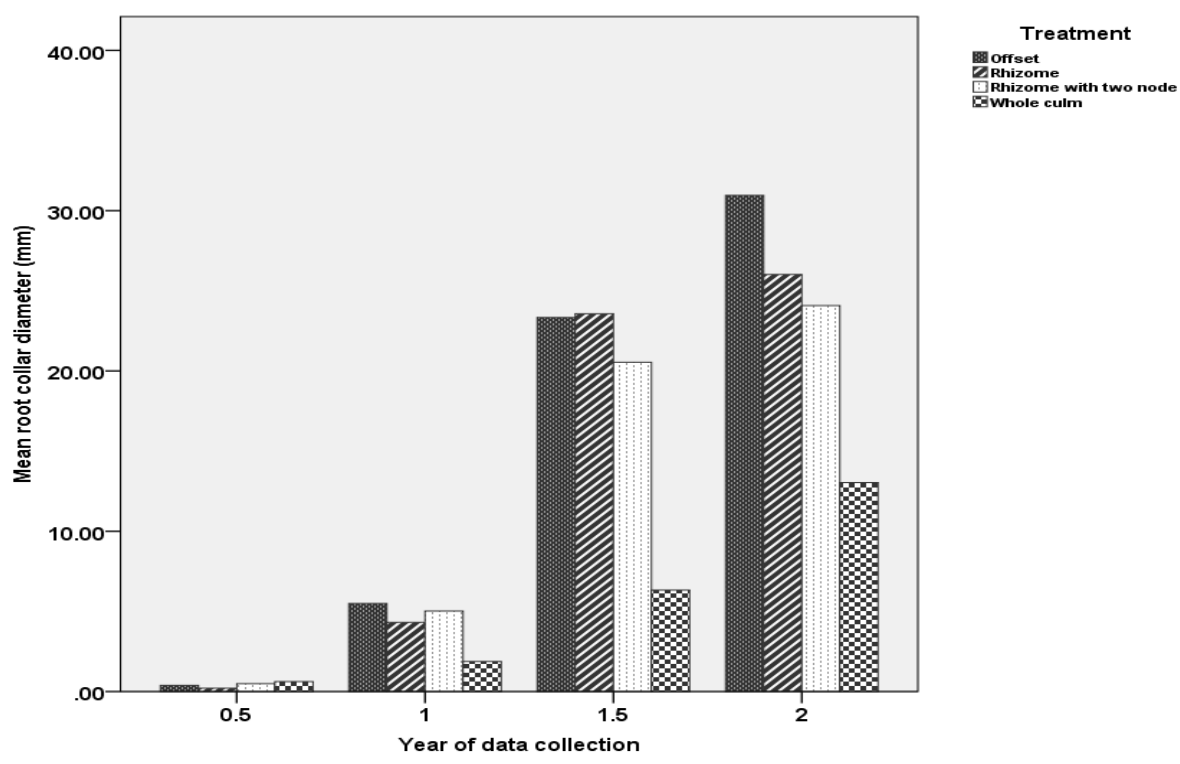

Figure c

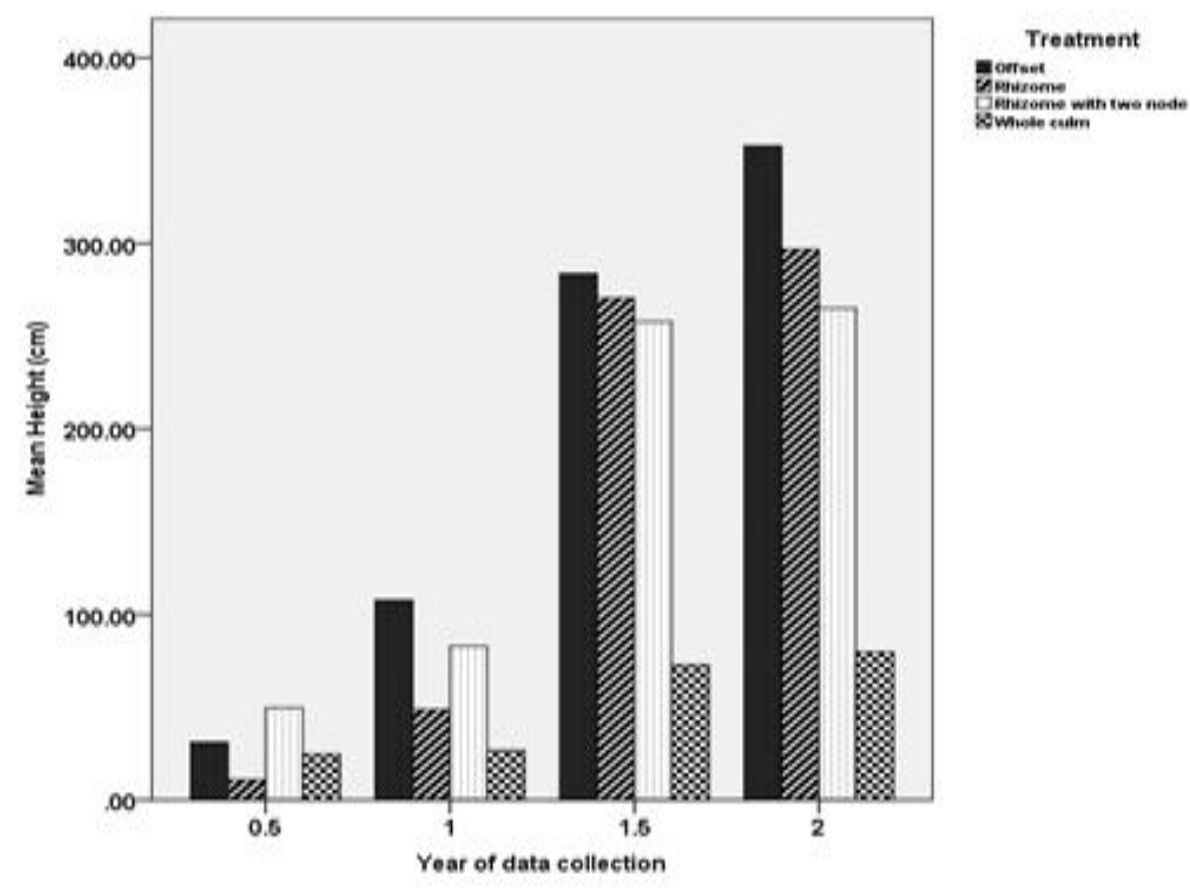

Figure 3: Effect of propaguoles type and time after planting on vegetative propagation of Oxytenanthera abyssinica

\section{Pearson correlation coefficients}

The correlation between a number of shoot sprout and age was described in table (3). The correlation between the number of shoot sprout and age $\left(\mathrm{r}=0.419^{* *}\right)$ was weak and positively correlated. It was significant at 0.05 and 0.01 level $(P=0.005)$ in table (3).

Table 3: Pearson correlation coefficients between numbers of shoot sprouts and ages

\begin{tabular}{|l|l|l|}
\hline Variables & No.of shoots & Time (year) \\
\hline
\end{tabular}




\begin{tabular}{|l|l|l|l|}
\hline \multicolumn{2}{|c|}{$\begin{array}{c}\text { Pearson correlation } \\
\text { No.of shoots }\end{array}$} & 1 & $\begin{array}{l}0.419^{* *} \\
\text { Sig. (1-tailed) }\end{array}$ \\
Time & $\begin{array}{l}\mathrm{P}=0.005) \\
\text { Pearson correlation } \\
\text { Sig. (1-tailed) }\end{array}$ & $\begin{array}{l}0.419 * * \\
(\mathrm{P}=0.005)\end{array}$ & 1 \\
\hline
\end{tabular}

\section{Conclusions and Recommendations}

The number and length of the emerged bamboo shoots were higher in rhizome-based propagation techniques than whole-Culm propaguoles. The poor performance of small-sized planting materials appears to be related to the lower amount of food reserve.

Propagation through off-set in the local community is traditionally known as old age methods of Oxytenanthera abyssinica propagation. However, it is mainly inappropriate for large-scale plantation, due to labor intensiveness, time consumption, transportation, and other logistical costs. According to the present findings, off-sets and rhizomes with two nodes had not shown big differences in the number of sprouted shoots and performances along with time trends.

According to the findings of this study, rhizomes with two nodes have proved to be the best propaguoles of Oxytenanthera abyssinica for large-scale propagation as well as for a small-scale plantation. During the experiment, the planting materials were significantly strained by termite infestation and water stress. Therefore, further research on disinfection treatments and other management practices are recommended to increase the persistence of new bamboo shoots. 


\section{Disclosure Statement}

The authors reported no potential conflict of interest.

\section{Funding}

The fund of the experiment was obtained from the Ethiopian Environment and Forest Research Institute.

\section{References}

[1.] Azene, B. (2007). Useful trees and shrubs of Ethiopia: Identification, Propagation and Management for 17 Agroclimatic Zones. Nairobi Kenya: World Agroforestry Centre, East Africa Region.

[2.] Abiy, A. (2013). Design and analysis of bamboo and E-Glass fiber reinforced epoxy hybrid composite for wind turbine blade shell.

[3.] Banik, R. L. (1995). A manual for vegetative propagation of bamboos. Noida, India.: International development research center UNDP/FAO regional forest research institute.

[4.] Bareja, B. G. (2010). Bamboo production and propagation methods.

[5.] Batabyal, S. and Tah, J. (2013). The response of vegetative propagation of Bambusa species under forest management. Research Journal of Biology, 1:40.44.

[6.] Demelash, A., Zebene, T., Yared, K.(2012). Effect of Storage Media and Storage Time on Germination and Field Emergence of Oxytenanthera abyssinica Seeds. International Journal of Basic and Applied Sciences, 1-10.

[7.] Demissew, S., Tesfaye, D., Kassahun, B., Mehari, A., Yared, K. and Negash, E. (2011). Mass flowering and death of bamboo: a potential threat to biodiversity and livelihoods in Ethiopia. Journal of Biodiversity and Environmental Sciences, 10.

[8.] Dereso, Y. (2019). Regeneration study of lowland bamboo (Oxytenanthera abyssinica A. R. Munro) in Mandura District, Northwest Ethiopia. Biodiversity International Journal, 18.

[9.] Kassahun, E. (2000). The Indigenous Bamboo Forests of Ethiopia: An Overview. Research Gate, 5.

[10.] Kassahun, E., Christerssion, S., Ledin, S.,Weih, M. (2002). Bamboo as bio-resource in Ethiopia: management strategy to improve seedling performance (Oxytenanthera abyssinica).Bioresource. Journal of Technology,88(1):33-39p.

[11.] Kleinhenz,V.and Midmore, D.J.2005. Aspects of bamboo agronomy. Journal of advance agronomy,74(1).

[12.] Mulugeta,L.(2013). Bamboo forest restoration through PFM: Experience from Masha. Briefing Note 4.

[13.] Regassa,T.,Dawit,S.,Mezgebu S., Mokonin,D.(2016).Adaptation and growth performance of different lowland bamboo species in Bako,West Shoa, Ethiopia.Journal of Natural Sciences Research.Vol.6,No,9.

[14.] Yeshambel, M.,Mengistu, U. and Getachew,A. (2011). The role indigenous bamboo species (Yusharia alpine and Oxytenanthera abyssinia) as ruminant feed in northwestern Ethiopia. Journal of livestock research for rural development, 23(9):250-258.

[15.] Yigardu, M. and Masresha, F. (2014). Propagation Techniques for Highland Bamboo (Arundinaria Alpina) in the Choke Mountain, Northwestern Ethiopia. ethiop.J.Agric.Sci. 24:23-36.

[16.] LUSO, Consult GmbH (1997). Study on Sustainable Bamboo Management (Final report). Hamburg, Germany.

[17.] Rao, R., Charla, B., Belcher, B., Karki, M.and Williams T. (1996). Bamboo, people and the environment. Volume (4). Socio-Economics and Culture, INBAR Technical Report No.8.

[18.] Ronald, P. (2005). Tropical Bamboos, Propagation Manual. International Network for Bamboo and Rattan (INBAR), Beijing, China.

[19.] Reddy (2006). Clonal propagation of bamboo (Dendrocalamus strictus). Current Science, 3.

[20.] Yared, K., Zebene, T., Abera, G. and Yigardu, M. (2017). Vegetative Propagation Techniques of Highland Bamboo (Yushaniaalpina) in Amhara Region, North-Western Ethiopia. World Scientific News, 1-15. 
[21.] Yohannes,W.G.,Debela,H.F.,Dereje,B.J.(2018).Socio-economic importance of highland bamboo (Yushania alpina K.Schum) and challenges for its expansion in Bibugn district, East Gojjam, ethiopia.Journal of Horticulture and Forestry,Vol. 11(2), pp. 32-41.

\section{Appendix}

Annex : ANOVA result along with time sequences

\begin{tabular}{|c|c|c|c|c|c|c|}
\hline Parameters & & $\begin{array}{ll}\text { Sum } & \text { of } \\
\text { Squares } & \\
\end{array}$ & df & $\begin{array}{l}\text { Mean } \\
\text { Square }\end{array}$ & $\mathbf{F}$ & Sig. \\
\hline \multirow{3}{*}{ No. of shoots } & $\begin{array}{l}\text { Between } \\
\text { Groups }\end{array}$ & 368.389 & 2 & 184.194 & 3.811 & 0.032 \\
\hline & Within Groups & 1595.167 & 33 & 48.338 & & \\
\hline & Total & 1963.556 & 35 & & & \\
\hline \multirow{3}{*}{ Survival rate $(\%)$} & $\begin{array}{l}\text { Between } \\
\text { Groups }\end{array}$ & 180.682 & 3 & 60.227 & .087 & 0.967 \\
\hline & Within Groups & 30526.316 & 44 & 693.780 & & \\
\hline & Total & 30706.998 & 47 & & & \\
\hline \multirow{3}{*}{$\begin{array}{l}\text { Root collar diameter } \\
(\mathrm{mm})\end{array}$} & $\begin{array}{l}\text { Between } \\
\text { Groups }\end{array}$ & 4426.883 & 3 & 1475.628 & 23.966 & 0.000 \\
\hline & Within Groups & 2709.205 & 44 & 61.573 & & \\
\hline & Total & 7136.087 & 47 & & & \\
\hline \multirow{3}{*}{ Height $(\mathrm{cm})$} & $\begin{array}{l}\text { Between } \\
\text { Groups }\end{array}$ & 432928.844 & 3 & 144309.615 & 18.284 & 0.000 \\
\hline & Within Groups & 347268.754 & 44 & 7892.472 & & \\
\hline & Total & 780197.598 & 47 & & & \\
\hline
\end{tabular}

